Lika Rodin

\title{
HORIZONS OF SUSTAINABILITY AND INDIVIDUAL ETHICS: THE CASE OF THE INTERNATIONAL SPACE STATION
}

Sustainability is a hot topic in contemporary politics both nationally and internationally. While the current framing of sustainability promoted at the international level favours social policies, doubts about their possible success are growing. If social aspirations are not realised, technological solutions to ecological problems might appear to be the only options. This study contributes to the field of sociology of the future. It explores and problematizes the technologically-oriented approach to sustainability. I consider a radical case of sustainable living - a spacecraft- looking at the emerging challenges to individual human ethics and the general order of sociality. More specifically, the largest contemporary manned space project, the International Space Station (ISS), is taken into analytical focus. With the help of the Foucauldian notion of governmentality, I examine routines and discourses related to the utilization of the life support system at the ISS in regard to human conduct, both terrestrial and extra-terrestrial. Mass-media materials comprise a large part of the dataset for this research. As demonstrated, techno-functionalism characterizes sustainability as governmental rationality. It imposes a subordination of individual human actors to the general order driven by systemic objectives frequently framed in pragmatic and technical terms. Specific practices, including ethically controversial ones, might be requested from individual humans in the name of the system's stability and efficiency. Those practices are naturalized and normalized within a truth regime constituted by scientific discourse, the authority of experts, media events and the related public discussions.

Keywords: governmentality, water recovery, life support, system approach, techno-functionalism

DOI: $10.17323 / 727-0634-2019-17-2-293-306$

Lika Rodin- lecturer in social psychology, University of Skövde, Sweden. Email: lika.rodin@his.se 
The notion of 'sustainability' or 'sustainable development' is highly prominent in political debates and decision-making nowadays. It was introduced in 1987 in the United Nations' report Our Common Future, widely known as 'the Brundtland Report'. In this document, sustainability was defined as the development that 'meets the needs of the present without compromising the ability of future generations to meet their own needs' (UN 1987: 6). Concern about the future of the planet and humankind had already been evident for decades. Back in 1972, MIT affiliates (Meadows et al. 1972) published an influential book entitled The Limits to Growth that turned attention to the potential catastrophic effects of natural resource exhaustion and population growth. Drawing on results obtained from computer simulations, the MIT scholars predicted that if humankind kept up with modernist trends of unrestricted economic growth, by the year 2100, terrestrial ecological systems would be at risk of failure. Throughout the second part of the twentieth century, continuous efforts were made by states and non-state actors to promote ecological objectives in national and international political programs. To consolidate efforts and cooperation around the issue of humankind survival, in 2015 the United Nations released a plan of action for sustainable development, Agenda 2030. Broadlty in line with leftist thinking of the time, the agenda primarily focused on various social policies, including fighting poverty and social exclusion, while paying less attention to the technological aspects of sustainability (UN 2015). This enthusiastic developmental vision, however, was challenged by scientific scepticism that pointed out that the economic redistribution crucial for balancing living conditions for groups and peoples around the globe would be difficult to achieve in the context of expanded market relationships (Randers 2012). If social aspirations are not realised, technological solutions to ecological problems might appear to be the only options.

This study is intended as a contribution to the field of sociology of the future (Wendell, Mau 1971). It explores and problematizes the techno-oriented approach to sustainability, claiming that disregarding the social dimension may shape the ontology and epistemology of human society and its management. I consider a radical case of sustainable living - a spacecraft- looking at the emerging challenges to individual human ethics and the general order of sociality. More specifically, the largest contemporary manned space project, the International Space Station (ISS), is taken into analytical focus. With the help of the Foucauldian notion of governmentality, I examine routines and discourses related to the utilization of the life support system on the ISS in regard to human conduct, both terrestrial and extra-terrestrial. Mass-media materials comprise a large part of the dataset for this research.

Sustainability as a resource for public management has been previously discussed in relationship to knowledge production and the politics of 'green governmentality' (Luke 1999; Rutherford 2007). These contributions, however, tended to draw on Foucault's inspired association of governmentality with 
biopolitics (e.g. Rutherford 2007). The current study questions the role of the prefix 'bio-' in the prospective management regime; it instead highlights technologization as the central component of contemporary governmental rationalities fashioning the futuristic imagery of sustainability. An ideal model of a sustainable system appears to be a well-tuned techno-biological composition in which human corporeality and subjectivity are turned into the system's operational elements.

The paper consists of four parts. Firstly, I will provide background information on the International Space Station, its history and operation. Secondly, the theoretical framework of the study will be presented, followed by a discussion of the research findings and the conclusion. I argue that a technologically-oriented definition of sustainability (1) subordinates individual human actors and their traditional conducts to the requirements of technological systems and (2) potentially undermines the very idea of individual self-determination, which is foundational to an efficient social policy regime in a democratic society (Sen 1993).

\section{The International Space Station: Brief history and operation}

As is well known, manned exploration of outer space started in 1961 with the one-hour and forty-eight minutes spaceflight of Russian cosmonaut Yuri Gagarin and continued through the next thirty years with Russian and American space missions. The history of long-term presence in outer space is frequently associated with the Russian space stations Salyut (1971) and Mir (1986), as well as with an American project, Skylab (1973), that allowed accumulation of knowledge and technological innovations in outer space exploration (Wieland 1998). Military-oriented and competitive in the beginning, space programs gradually acquired a more civic and cooperative character, thanks to the various international treaties (Harris 2009). High costs and the risk of failure measured by human lives facilitated the establishment of international agreements around space projects. In 1993, according to one version, RSA Director General Yuri Koptev and NPO Energia Designer General Yuri Semenov contacted NASA Administrator Daniel Goldin with the idea of launching an international space station. This communication eventually resulted in a cooperation contract between Russia and the United States that was signed in 1994 (Energia n.d.).

From the American side, the aspiration for long-term missions was clearly formulated already in 1982 by Ronald Reagan in one of his public speeches, followed by a special assignment to NASA to initiate a construction of the space station Freedom. However, in subsequent years, the attention of the US space agency shifted to the Space Shuttle fleet, and overall objectives for space exploration turned to the issues of military defence (Harris 2009). Civic priorities in outer space enterprise re-emerged in the American political agenda under the George H.W. Bush administration in the 1990s (ibid.), a development that facilitated cross-national collaboration. 
The International Space Station is a low-orbit modular spacecraft, moving at the altitude $350-400 \mathrm{~km}$ above Earth (NASA 2011a) with an approximate speed of 17,500 miles per hour, orbiting the planet every one and a half hours (NASA 2015b). It consists of sixteen units (modules) that can be assembled differently to address various mission objectives. The station is logistically divided into two segments - Russian (RS ISS) and American (AS ISS). The RS ISS includes two operational units (a service module Zvezda and a functional cargo block Zarja), two research modules and docking compartments. The AS ISS is comprised of three laboratory units (U.S. Destiny, European Columbus and Japanese Kibo), three connected nodes (Unity, Harmony and Tranquility), and a number of supplementary units (NASA 2015a). The Zarja module, based on Russian Mir station technologies, was the first one launched into orbit in 1998. The next two years of construction were hampered by economic difficulties and technological failures on both the Russian and American sides (Harris 2009) until the first expedition arrived in 2000 (NASA 2015b). The initial life span of the station was calculated to 2020, but the space agencies attempted to negotiate prolongation of the ISS operation until 2024 (NASA 2014). Sixteen countries are involved in the project, represented by twenty space agencies all around the globe (NASA 2015a). By now, fifty-six missions to the International Space Stations have been completed by international crews with an average stay of two to six months. The size of the crew vary from three to six members. The station serves several important objectives, including research, observation and education. The total costs of the project are somewhat difficult to estimate. In 2014, NASA reported spending \$75 billion on ISS programmes, with prospective annual costs of \$3-4 billion (NASA 2014: i). Contributions to the project by other partners are less publicly available.

The environmental control and life support system (ECLSS) is one of the most significant elements and a constant concern for ISS developers. The American ECLSS includes 'atmosphere revitalization', 'water recovery and management', 'metabolic waste management', 'atmosphere control and supply', 'temperature and humidity control' and 'fire detection and suppression' (Wieland 1998:3). The underlying logic emphasizes rational use of irreplaceable resources, meaningful integration of regeneration technologies, and a pragmatic balance between reliability and redundancy (ibid:22). The Russian ECLSS has a different architecture: apart from the aforementioned elements, facilities typically defined by NASA as 'crew system' (e.g. 'food storage and preparation', 'refrigerators/freezers', 'extravehicular activity support', 'whole body cleaning' and 'housekeeping') are traditionally included in the Russian ECLSS (ibid:3). Self-efficiency of the life support system is recognized across organizational cultures as an important requirement due to high costs of supply delivery (Mitchell et al. 1994) and risks of delay associated with technical and economic restrictions. There is an emergency stock that is supposed to support living on board for several weeks (Bobe et al. 2010). 
The water reclamation system is a central concern of the current study. As described by NASA experts, it collects the wastewater on the ISS and processes it into potable water. The wastewater includes cabin humidity condensate, Sabatier product water (water obtained by processing naturally accumulated carbon dioxide and hydrogen, see NASA 2011b), and crew member urine (Pruitt et al. 2015: 1; see also NASA 2008). The Russian system additionally includes condensate from the vitamin greenhouse (Bobe et al. 2016). The American system has two elements: a Urine Processor Assembly (UPA) and a Water Processor Assembly (WPA). In UPA, urine is sent to a centrifuge in which low pressure is sustained to obtain water vapour that is further turned into a condensate, additionally cleaned and further mixed with the wastewater supplied to WPA. The sediment left after the distillation is collected, compressed and sent back to Earth with logistic vehicles. The capacity of UPA can satisfy the needs of a six-member crew. It was initially thought to reclaim $85 \%$ of the water from urine, although in practice this level turned to be difficult to sustain (Pruitt et al. 2015:5). In WPA, wastewater and water obtained from urine is cleaned of gases, hard materials and various contaminants with the help of chemical reactions and high temperatures. The product water is considered potable. It is carefully tested and supplied to the cabin for diverse uses, including drinking (ibid.). Even if the goal of making the system fully self-efficient is not achieved, the water reclamation system significantly lessens the need for resupply (NASA n.d.; Bobe et al. 2010). As stated by an ISS programme manager: 'Recycling will be an essential part of daily life for future astronauts, whether on board the space station or living on the moon' (Curie, Morcone 2008).

The Russian segment of the ISS has a separate system of water management grounded in a historically distinctive philosophy. More specifically, UPA is disconnected from other processors, and water recovered from urine is mainly used for hygienic needs and for the generation of oxygen (Wieland 1998; see also Mitchell et al. 1994; Bobe et al. 2010). For this reason, the crew is more dependent on the water resupply. It should be mentioned that water recycling had been implemented already in the earlier Russian space stations. Mir had a water and urine processors that allowed a considerable reduction of resupply missions (Mitchell et al. 1994; Bobe et al. 2010). This technology served as a prototype for the current mechanism used at RS ISS (Bobe et al. 2016). The difference in Russian and American water recovery architecture is reflected not only in technical reports (e.g., Wieland 1998; Mitchell et al. 1994) but also in public discussions.

\section{The Foucauldian notion of governmentality}

The notion of 'governmentality', developed by the French philosopher Michel Foucault in the late 1970s, will assist the analysis of framing sustainability in the context of radical sustainable living. Governmentality is famously 
understood as a regime of management characterized by emphasis on individual's self-regulation in distinction to one's automatic subjection to the power command. It is, in other words, at the intersection of power and agency that governmentality operates (Foucault 1997), ensuring the (re)production of a multifaceted and unfixed, but still relatively stable over time, social order (Dean 2010). Individual sovereignty then turns out to be a 'normalized' one (Rutherford 2007), serving as a precondition for 'governing at a distance' (Rose, Miller 1992). What is important to remember is that governmentality does not limit itself to the analysis of state-based regulation, but has a potential to account for the plurality of domains in which governance is exercised (Rutherford 2007).

Governmentality is further operationalized into two elements: techne and 'governmental rationalities' (Dean 2010). While the first component refers to the materiality of regulation, including its methodology and practical applications, the notion of rationalities signifies the symbolic resources employed. As Dean (2010: 18-19) stated, rationalities of government are 'forms of thinking' attempting 'to be relatively clear, systematic and explicit about...how things are or how they ought to be'. Governmental rationalities are embedded in governmental technologies simultaneously legitimizing them. The idea of governmental rationalities will be central to my empirical analysis, since governing, after all, is about 'the construction of certain truths' (Rutherford 2007: 293).

\section{The controversy around the issue of water recycling: a research conversation}

In August 2015, The Guardian published a provocative article addressing the issue of water recovery on the ISS. The author (Brait 2015) described a paradigmatic difference in recycling mechanisms employed in the Russian and American segments. NASA experts were cited who expressed confidence in the quality of the potable water in the American part of the ISS. They even drew a parallel with ordinary bottled water available on Earth. Simultaneously, the presence of two distinct approaches to water reclamation on the ISS was justified with reference to the benefits for the overall reliability of life support. This article caused a vigorous discussion in the commentary section accompanying it. In all, 236 responses were posted, and the article was shared 1485 times in the two days after the publication. This media discussion has become the focus of my inquiry. I analysed discourses related to the utilization of the water recovery systems on the ISS, looking at the relationships between sustainability and human conduct. The study dataset included the original article and the related comments.

The Guardian is popular among left-leaning readers (Mayhew 2017), who typically consider themselves to be at the vanguard of social progress. The readership sample utilized in the current study is self-selected, reflecting to some extent the overall level of public engagement with the topic. Therefore, 
generalizations made in the analysis should be considered in the context of a specific population segment and the general public agenda. Critical discourse analysis - a method recognizing intimate relationships between power and representations (Fairclough 1995; Lirola, Chovanec 2012)—was applied to process the data.

After an initial screening, fifty-three responses were excluded from the dataset as not informative or relevant to the study. The remaining materials were coded inductively, with a focus on the plurality of significations. The same message could be assigned to more than one signification category. Furthermore, the number of 'recommendations'/'likes' given to every response by the participants in the discussion was considered. Table 1 presents the result of this procedure in a form of a specific discursive catalogue. According to a German-based Althusser-inspired group of scholars, Projekt Ideologietheorie, ideological effects can be achieved, apart from the working of the dominant discourses, by 'horizontal socialization' (Rehmann 2013). Discourses that have emerged in the media discussions do not stand only within the written communication itself. Being publicly available, they might appeal to other readers who did not take an active part in the media conversation (Althusser 2001). To some extent, these effects can be approximated by the number of 'likes' received by different signification categories.

Table 1

Discursive catalogue of the on-line discussion

\begin{tabular}{lcc}
\hline \multicolumn{1}{c}{ Signification categories } & $\begin{array}{c}\text { Frequency of comments in } \\
\text { the entire data set, } \%\end{array}$ & $\begin{array}{c}\text { 'Likes' } \\
\text { Nition }\end{array}$ \\
\hline Normalization & 29.3 & 159 \\
Questioning normalization & 19 & 89 \\
Critique of terrestrial food and drink quality & 17.5 & 80 \\
Cultural differences/divisions & 16 & $111^{*}$ \\
Commercialization & 9.2 & 27 \\
'Bullying' of politicians and celebrities & 5 & 45 \\
Critique of the newspaper & 4 & 13 \\
\end{tabular}

*The relatively high proportion of those who have chosen to respond to this discourse anonymously may reflect latent nationalism/racism.

A leading interpretation of the situation at the ISS - normalizing discourse $(29.3 \%)$ - drew a parallel with the natural order of terrestrial water circulation. In the original article, the consumption of water recovered from urine was presented as necessary, safe and compatible with terrestrial realities. Along the same line of argument, one reader stated: 'Most of the water we 
drink is recycled from something - it evaporates, turns to clouds, falls into rivers, ends up in reservoirs and we drink it' (reader 'djw300'). 'Nothing new', another reader concluded, 'We're just accustomed to a longer cycle' (reader 'Velska'). The biosphere in this context was imagined as a closed, self-efficient system similar to the life support system on the ISS; technologically managed procedures unproblematically replaced natural processes (see, Höhler 2010). Alternatively, the consumption of recycled water was said to be already an integral part of terrestrial life, especially in urban areas. One reader noted: 'As a Londoner, I was under the impression that the water I drink here has already passed through several other people' (reader 'stevehulk'). In this context, recycling appeared more of a technical solution in the management of large populations. There were also responses that praised the new technology, stating that those who do not accept or even oppose it are less educated or knowledgeable about the procedures employed. The technology was seen to be a 'good science for survival' (reader 'Kwame Okoampa-Ahoofe') that should be used back home to ensure human operation in extreme situations of natural disasters or war conflicts. Overall, the claim was made to 'get over' ethical concerns and accept the existing state of affairs.

After the discourse of acceptance and normalization followed comments that questioned this attitude in different ways (19\%), not rarely by subverting the meanings or by making jokes. Challenging the normalization involved a number of modalities. The readers problematized the equation of the terrestrial ecological circle with the technological process of water recovery installed on the ISS. They further argued that practices of consumption of recycling products do not fit the media-promoted romanticized by Sci-Fi image of a spacefarer. Some participants of the discussion pointed out the puzzling effects of space science on the daily lives of people on the ground: 'First it was non-stick frying pans and digital watches. I don't like the way this space-stuff is developing' (reader 'ejmd'). Finally, several readers directly emphasized the ethical aspect of water recycling, claiming that consumption of the water recovered in this way would require stepping over certain ethical boundaries or taboos. One reader highlighted possible psychological externalities of the radical approach to water recovery during its development: 'Spare a thought for the engineers on the ground who had to test and debug the recycling system before it flew. I'd imagine that wasn't a pleasant assignment. I'm sure you can do tests, but there's only one quick way to be sure it's drinkable...' (reader 'smed54235'). Overall, however, a number of those who supported the innovation obviously outnumbered those expressing concerns about it.

Apart from the two most common discourses, five other signifying categories have surfaced in the dataset. In all, $17.5 \%$ of the replies turned the whole story around, criticizing the quality of terrestrial food and drinks: if the recycled water on the ISS tastes like bottled water, as NASA experts claim, what are we drinking or eating? Another $16 \%$ of responses addressed cultural 
differences and political divisions; national stereotypes and political ideologies were frequently employed to construct 'us' versus 'them'. Yet another group of readers $(9.2 \%)$ turned to possibilities or practices of extracting economic value from the shortage of water in some regions where the space technologies can be utilized for profit. Another $5 \%$ of responses twisted the topic to criticize or tease political leaders and celebrities. Finally, $4 \%$ criticized the newspaper for the improper or uninteresting publication. For this study, the most prominent discourse-normalization - will be further analysed.

\section{Sustainability as governmental rationality}

In line with the Foucault-inspired view (Rutherford 2007), the regime of sustainability at the ISS, including water recycling, is not just an empirically given reality, but a domain of governing in which practices of ECLSS utilization are turned into an intelligible and manageable object. Discourses surrounding water recycling policies on the ISS highlight resource scarcity, costs of resupply and the need of the space station to achieve relative autonomy from any type of external resources with the emphasis on what Baudrillard termed 'a minimalist principle of "survival"' (cit. in Höhler 2010: 50). Overall, the prospective development of the space station is framed in functionalist terms. It rests on the idea of a controlled 'closed loop system' (Harris 2009) and promotes the primacy of macro-phenomena. As it appeared in the analysed materials, this system is increasingly techno-biological, prioritizing technological requirements and the related technological solutions even for biologically based processes. In such an increasingly technologizing environment, an individual (corporeal and ethical) becomes an element of the machinery.

System thinking has been present in social and natural sciences for centuries, including in the emerging domain of ecology (Höhler 2010). Updated by new discoveries of cybernetics, the systems approach, at the beginning of the 1980s, laid a foundation for innovative experiments with sustainable living, such as the Biosphere 2 'living laboratory' (ibid: 40). Supported by civil society enthusiasts, the scientific community, and NASA experts, the project aimed at constructing an enclosed self-efficient habitat on several acres in a southwestern region of the US. It included a different types of land hosting various plants and animals, and eight humans. Biosphere 2 become an exemplary implementation of system thinking in ecological practice. Two newly emerged disciplines'biospherics' and 'ecotecnics' - underpinned the construction and operation of the experimental environment by a practical interlocking of biologically and technologically oriented modes of systems theory. The result was astonishing:

Biosphere 2 conveyed an image of containing pure Earthly nature under its glass dome. The nature of Biosphere 2, however, was stretched like a thin organic skin on the surface of huge machinery. An intricate network of more than 2000 sensors, the 'nerve system' of the planet, continuously monitored 
the designated parameters to effect stability and safety of the life-support system. A circuit of cables, ventilators, pumps, and turbines was responsible for circulating, flushing, cleaning and cooling the air and the water, for moving wind and waves, and for regulating the climate - air pressure, temperature, humidity, precipitation (Höhler 2010: 49).

This 'denature' appeared as an ephemeral phenomenon and an analogue to a life support system constituted by 'environmentality' (ibid:50), a regime of management that imagines 'the natural' in pragmatic and technical terms as 'an object of detention, exploitation, enhancement and optimization' (ibid).

The system-oriented epistemology, as in the current study, facilitates a discourse of necessity arising out of systemic needs or challenges: something should be done to reduce risks or prevent failures. This rhetoric might lead to a demand for adjustment to certain technical requirements imposed on humans, including modifications of individual ethical frameworks beyond possible taboos or other ethical boundaries. Ethically controversial practices, such as the consumption of one's own waste, have been naturalized and normalized within a specific truth regime constituted by scientific discourse and the authority of experts. The strategy of normalization, moreover, employed a technique of comparison by drawing a parallel between the radical sustainable reality of the ISS and terrestrial reality (e.g. the comparison of the processed water with bottled water or of the recycling cycle on the ISS and the natural water cycle on Earth). Truth, generated by the mass media on the nature and effects of water recovery on the ISS, 'recruited' a large portion of readers, shaping their conduct and provoking their engagement in enthusiastic search for new arguments supporting the picture presented.

The issue introduced in The Guardian highlights ideological differences. In a technical sense, some options for the recovery of potable water from urine were available already on the early Russian space stations, but were not utilized. Medical doctors involved in the Russian space programme initially insisted that cosmonauts drink exclusively terrestrial water. Later on a gradual normalization of processed water started with the consumption of water obtained from humidity. Russian engineers capitalized on reclamation as a mean to reduce the logistic burden (Mitchell et al. 1994). In distinction, the American approach from the very beginning had being dominated by technical thinking (Harris 2009) that favours full water recycling and reuse. This techno-functionalist vision may become dominant in the context of challenging interplanetary missions and expanding neoliberal logic of cost efficiency. A comlpete water recovery and reuse (including recovery of potable water from urine) is already assumed to be a model for future development of the Russian life support system (Bobe et al. 2010). As above discussed, such a regime tends to prioritize technological framing of life and technological solutions.

As commentators indicated, for quite a long time NASA did not show much enthusiasm for the meaningful incorporation of social issues into its research 
agenda. Even when social scientists were finally included in the space program, they occupied a marginal organizational position (Harris 2009). Considering a possible role of the behavioural and social sciences, one should, however, keep in mind that their effects are twofold. On the one hand, social and behaviour disciplines can help get a better understanding of the challenges that cosmonauts and astronauts might face during their missions. On the other hand, as Foucauldian studies have shown (Rose 1998), human sciences historically emerged to serve the interests of power. At the end of the day, rationalities which arose around the issue of water recovery are technologies of power that employ psychological tools to shape ethical guidelines of individuals both on the ground and aloft, and eventually to serve the purposes of social engineering (see, Harris 2009).

Finally, in the liberal perspective, radical sustainability framed in technofunctionalist terms might result in a general disregard of diversity perceived in the context of system thinking as redundancy. In other words, concerns for individual needs, preferences, self-actualization, self-determination and selfexpression - integral elements of post-industrial, globalized and liberal orderare at risk of disappearing. In distinction to the early enthusiastic view (typically grounded in an evolutionist approach) on the survival and proliferation of cultural diversity in the context of interplanetary expeditions and space colonies, the current study argues that, with system thinking, differences could be accounted for only when they serve certain functional ends. This is indeed the case of the ISS, where two distinct systems of water recovery are kept to ensure the overall reliability of life support.

\section{Conclusion}

This study has addressed the issue of sustainable living by looking at the emerging challenges to individual human ethics on the ISS and beyond. $\mathrm{Hu}-$ man diversity operationalized by possibilities of self-determination is currently viewed as a foundation of individual and social well-being, and therefore a prerequisite for efficient social politics (Sen 1993). The technological approach, as I have argued, tends to undermine actual individual sovereignty and, correspondingly, individuals' prospective for social-psychological welfare. In this context, governmental rationalities are called into being to normalize the unfavourable conditions constructing, with the help of public rhetoric and scientific knowledge, compliant subjects of techno-functionalism.

To be sure, the low-orbit experiments with water recycling are not as far away from our daily lives as might be assumed. First of all, efforts are being made to implement space innovations in the terrestrial context (NASA 2015c) and, as we found in the cited public discussion, there is a request to integrate those novelties for managing the problems that populations can face on Earth. These technologies are in fact already in use in some parts of the world (Thomas 2016). Second, public and scientific imagery has been considering habituation in space- 
craft as a prototype for sustainable life in general, the idea having manifested itself in Biosphere 2. This model might be especially plausible in the event of the predicted ecological crisis actually occuring. However, not everyone is (yet) interpellated by the techno-oriented discourse of sustainability. As this analysis has shown, people on the ground (as well as some spacemen and -women) may resist the reductionist approach, upholding instead romantic ideals of space exploration and ethical individual norms or preferences (see a description of the signifying category 'questioning normalization'). The question, however, remains: does advanced sustainability unavoidably involve a request for reshaping individual ethical conduct in line with the ideals of efficiency and functionality? The authors of 'the Brundtland Report' (UN 1987: 7) might have been aware of this stating in the late 1980s: 'We do not pretend that the process is easy or straightforward. Painful choices have to be made. Thus, in the final analysis, sustainable development must rest on political will.'

\section{References}

Althusser L. (2001) Ideology and Ideological State Apparatus. B. Brewster (transl.). In: Lenin and Philosophy and Other Essays. New York: Monthly Review Press: 85-126.

Bobe L., Gavrilov L., Kochetkov A., Kurmazenko E., Andreichuk P., Zelenchuk A., Romanov C. (2010) Regeneration of Water and Atmosphere at the Space Station: The Experience of the Orbital Stations Salyut, Mir and ISS, the Prospects for Development. Conference paper, IAC-10-A1.6.6., 27.10.2010. Available at: http://www.niichimmash.ru/ press/publications/regeneratsiya-vody-i-atmosfery-na-kosmicheskoy-stantsii-opyt-orbitalnykh-stantsiy-salyut-mir-i-mks-p/ (accessed 24 February 2019).

Bobe L., Kochetkov A., Tsygankov A., Korobkov A., Romanov S., Zeleznyakov A., Andreychuk P. (2016) Design and Operation of Water Recovery Systems for Space Stations. $46^{\text {th }}$ International Conference on Environmental Systems ICES-2016-2810-14 July 2016, Vienna, Austria. Available at: https://tu-ir.tdl.org/ttu-ir/bitstream/handle/2346/67479/ICES_2016_28. pdf? sequence $=1$ (accessed 15 November 2018).

Brait E. (2015) US Astronauts Drink Recycled Urine Aboard Space Station But Russians Refuse. The Guardian, August 26. Available at: https://www.theguardian.com/science/2015/ aug/26/us-astronauts-recycled-urine-international-space-station_accessed 17 November 2018).

Curie M., Morcone J. (2008) New Water Reclamation System Headed for Duty on Space Station. NASA News Releases. Available at: https://www.nasa.gov/home/hqnews/2008/may/ HQ_08119_ISS_Water_System.html (accessed 9 October 2018).

Dean M. (2010) Governmentality: Power and Rule in Modern Society. Los Angeles: Sage.

Energia, S. P. Korolev Rocket and Space Corporation (n.d.). The Project History. Available at: https://www.energia.ru/en/iss/iss-history.html (accessed 9 October 2018).

Fairclough N. (1995) Critical Discourse Analysis: The Critical Study of Language. London: Longman. 
Foucault M. (1997) Ethics: Subjectivity and Truth. The Essential Works of Michel Foucault, 1954-1984. New York: The New Press.

Harris P. R. (2009) Space Enterprise: Living and Working off World in the $21^{\text {st }}$ Century. Chichester, UK: Springer.

Höhler S. (2010) The Environment as a Life Support System: The Case of Biosphere 2. History and Technology, 26 (1):39-58.

Lirola M. M., Chovanec J. (2012) The Dream of a Perfect Body Come True: Multimodality in Cosmetic Surgery Advertising. Discourse \& Society, 23 (5): 487-507.

Luke T. (1999) Environmentality as Green Governmentality. In: E. Darier (ed.) Discourses of Environment. Oxford: Blackwell: 121-151.

Mayhew F. (2017) How Daily Newspaper Reads Voted by Title in 2017 General Elections. PressGazette. Available at: http://www.pressgazette.co.uk/how-daily-newspaper-readersvoted-by-title-in-the-2017-general-election/ (accessed 23 October 2018).

Meadows D.H., Meadows D. L., Randers J., Behrens III. W. (1972) The Limits to Growth: A Report for the Club of Rome's Project on the Predicament of Mankind. New York: Universe Books.

Mitchell R.M., Bagdigian R.L., Carrasquillo D.L., Carter G.D., Franks D. W., Kolder Jr., Hutchens C.F., Ogle K. Y., Perry J.L., Ray S.D. (1994) Technical Assessment of MIR-1 Life Support Hardware for the International Space Station. NASA TM-108441. Available at: https:// ntrs.nasa.gov/archive/nasa/casi.ntrs.nasa.gov/19940026875.pdf (accessed 02 October 2018).

NASA (2008) International Space Station: Environmental Control and Life Support System FS-2008-05-83-MSFC 8-368788. Available at: https://www.nasa.gov/centers/marshall/pdf/104840main_eclss.pdf(accessed 22 November 2018).

NASA (2011 a) Higher Altitude Improves Station's Fuel Economy. Available at: https://www. nasa.gov/mission_pages/station/expeditions/expedition26/iss altitude.html (accessed 22 November 2018).

NASA (2011b) The Sabatier System: Producing Water on the Space Station. Available at: https://www.nasa.gov/mission_pages/station/research/news/sabatier.html (accessed 22 November 2018).

NASA (2014) Extending the Operational Life of the International Space Station until 2014. Audit Report IG-14-031. Available at: https://oig.nasa.gov/audits/reports/FY14/IG-14-031. pdf (accessed 22 November 2018).

NASA (2015a) Reference Guide of the International Space Station. Available at: https://www. nasa.gov/sites/default/files/atoms/files/np-2015-05-022-jsc-iss-guide-2015-update-111015508c.pdf (accessed 23 October 2018).

NASA (2015b) ISS facts! Available at: https://www.nasa.gov/feature/iss-facts (accessed 23 October 2018).

NASA (2015c) International Space Station Benefits for Humanity. 2nd Edition. NP-201501-001-JSC. Available at: https://www.nasa.gov/sites/default/files/atoms/files/jsc_benefits_for_humanity_tagged_6-30-15.pdf (accessed 5 October 2018). 
NASA (n.d.) Water Filtration Challenge. Available at: https://www.jpl.nasa.gov/edu/teach/ activity/water-filtration-challenge/ (accessed 5 October 2018).

Pruitt J. M., Bagdigian L., Kayatin M. J. (2015) Upgrades to the ISS Water Recovery System. $45^{\text {th }}$ International Conference on Environmental Systems, 12-16 July 2015, Bellevue, Washington. Available at: https://ntrs.nasa.gov/archive/nasa/casi.ntrs.nasa.gov/20150019533.pdf (accessed 10 October 2018).

Randers J. (2012) 2052: A Global Forecast for the Next Forty Years. White River Junction, VT: Chelsea Green Publishing.

Rehmann J. (2013) Theories of Ideology: The Power of Alienation and Subjection. Boston: Brill.

Rose N. (1998) Inventing Our Selves: Psychology, Power, and Personhood. Cambridge: Cambridge University Press.

Rose N., Miller P. (1992) Political Power beyond the State: Problematics of Government. The British Journal of Sociology, 43 (2): 173-205.

Rutherford S. (2007) Green Governmentality: Insights and Opportunities in the Study on Natures Rule. Progress in Human Geography, 31 (3):291-307.

Sen A. (1993) Capabilities and Wellbeing. In: M. Nussbaum, A. Sen (eds.) The Quality of Life. Oxford: Clarendon Press: 30-53.

Thomas D. (2016) Four Ways NASA is Teaching us How to Live More Sustainably. $B B C$ : Business. Available at: http://www.bbc.com/news/business-35362202 (accessed 15 October 2018).

UN (1987) Our Common Future. Report of the World Commission on Environment and Development. Available at: http://www.un-documents.net/our-common-future.pdf (accessed 11 November 2018).

UN (2015) Transforming Our World: The 2030 Agenda for Sustainable Development. Available at: http://www.regeringen.se/48e36d/contentassets/a69f085ada12410989115alff64be6d8/ att-forandra-var-varld-agenda-2030-for-hallbar-utveckling (accessed 27 October 2018).

Wendell B., Mau J.A. (eds.) (1971) The Sociology of the Future: Theory, Cases, and Annotated Bibliography. New York: Russell Sage.

Wieland P. O. (1998) Living Together in Space: The Design and Operation of the Life Support Systems on the International Space Station. Vol 1. NASA/ TM-206956. Available at: https://spaceflightsystems.grc.nasa.gov/repository/NRA/tm206956v1 \%20living\%20together\%20\%20in\%20space.pdf (accessed 13 November 2018). 